Journal of Thermal Engineering, Vol. 6, No. 6, Special Issue 12, pp. 420-433, December, 2020

Yildiz Technical University Press, Istanbul, Turkey

\title{
DEVELOPMENT OF AN EFFICIENT T-TYPE STRAINER WITH ITS PERFORMANCE EVALUATION
}

\author{
Gaurav P. Mahajan ${ }^{1, *}$, R S Maurya1
}

\begin{abstract}
Strainers are devices used in process industry to protect mechanical equipment from getting damaged due the impurities in process fluid. Hence, performance of a strainer has a direct impact on the performance of the process plant. Present work deals with a methodology to model a T-type strainer using CFD tools, investigating its performance, proposing more efficient model and investigating their performance. Numerical model compares well with the experimental data. Five modifications in the existing strainer are proposed by introducing additional punch plate ahead of meshing element. Another significant modification proposed is creating offset across strainer for inlet and outlet of flow. These arrangement increases the net pressure drop across strainer but significantly improves the flow distribution for longer life of the strainer. Increasing body size of strainer and hole of the punch plate is found to reduce the impact of increased pressure drop. These conclusions are important for improving and redesigning an efficient $\mathrm{T}$-strainer.
\end{abstract}

Keywords: Porous Jump, CFD, Strainer, Porous Media, Pressure Drop

\section{INTRODUCTION}

Strainer is a filtering device which helps to remove particulates from fluid or gas flow to protect sensitive downstream equipments. It collects dirt and debris without hampering flowing system's performance significantly. Usually, they are placed before pump, compressor, turbines, automatic valves and other inline equipment to protect them. Absence of strainers in a process line could be one of the main reasons for the requirement of very frequent maintenance. Strainers of different designs are used for diverse applications - flat type, cone and basket type, Y-type, T-type and vertical basket type. Figure 1 shows quarter vertical cut section of a T-type strainer. The basic components of a strainer are - container, wire mesh, punch plate and orifice. Container is designed to fit with piping system. The elements of strainer rest on sitting in the container. Wire mesh is actual filtering element which is made up of metal wires. Mesh metal wire diameter and mesh count varies as per application. Punch plate supports thin wire mesh which is relatively thicker than wire mesh and placed just outside or inside of it. Wire mesh and punch plate are held at their respective places by an annular ring-shaped structure called as orifice. This arrangement causes decrease in diameter of inlet pipe at strainer entry and thus produces effect of orifice.

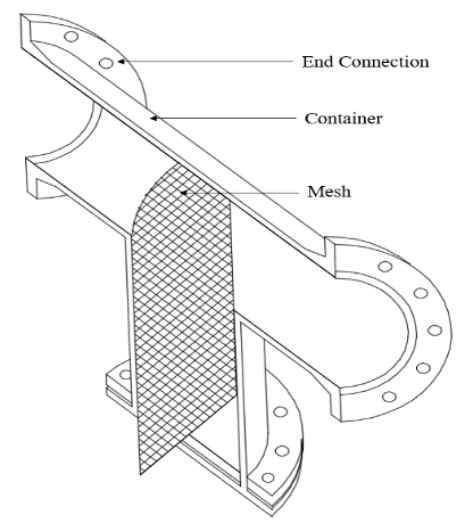

Figure 1. Cut view of T-type strainer

This paper was recommended for publication in revised form by Assigned Editor Mustafa Kilic

${ }^{I}$ Department of Mechanical Engineering, SPCE, University of Mumbai, Maharashtra, India

${ }^{*} E$-mail address: gmahi1193@gmail.com ${ }^{*}$

Orcid id: 0000-0003-4100-7252, 0000-0002-0564-1603

Manuscript Received 09 August 2018, Accepted 21 September 2018 
Debris particle flowing with fluids is either trapped in the mesh cavity or blocked. This results in reduced available opening for flow. Strainer sizing and selection are critical to insure cleaning cycle time, particle size retention and pressure drop requirements. Predicting possible pressure drop across a strainer is an important part of overall process system design. This information is generally provided by manufacturer in the form of performance data sheet or semi-empirical method present in various literatures. On many instances it is observed that the actual pressure drop through strainer comes out to be significantly different than what predicted by semi-empirical method.

Characterizing an industrial strainer regarding its hydraulic performance is a challenging task. Experimental testing of the device is reliable but time-consuming methodology. Few researchers tried theoretical and numerical approach to overcome with partial success. In a work on temporary conical strainer, Carlomagno et al. [1] developed a theoretical-experimental model to characterize the pressure drop and mechanical resistance. They used 6 inch cone geometry, with $40 \%$ porosity and a base angle of $81.35^{\circ}$ with mass flow is $0.2 \mathrm{~kg} / \mathrm{s}$. They investigated the impact of cone angle, porosity and thickness and their effects on the performance of strainer. The clogging characteristic was also investigated. Through a simple experimental and analysis, Kang et al. [2] investigated flow through wire screen mesh and derived a proportional factor between the velocity of fluid and head loss which can estimate coefficient of discharge, $\mathrm{C}_{\mathrm{d}}$, for wire mesh. Using PHOENICS computer code, Erdal and Andersson [3] carried out a 2D-numerical investigation for flow through a single-holed plate. They concluded that turbulent kinetic energy and pressure drop are more grid-sensitive than the mean axial velocity in the down-stream of the orifice. Flow through an oil filters has been numerically investigated by Iliev et al. [4]. They used Navier-Stokes-Brinkman system successfully to simulate flow through plain and porous media both. Malavasi et al. [5] performed an experimental work to investigate the requirement of the pressure losses through sharp-edged perforated plates with key parameters of geometrical and flow variables. They studied the dependency of pressure loss coefficient to the Reynolds number, the equivalent diameter ratio, relative thickness and the number and deposition of the hole. Filho et al. [6] carried out a numerical work to investigate pressure loss across perforated plates used in pressurized water reactors. They concluded that the standard K- $€$ turbulence model is a good compromise between computational time and accuracy. Tekam et al. [7] presented a comparison between numerical and experimental methods to predict the efficiency of an automotive oil strainer. Gaurav et al. [8] carried out a numerical investigation of a T-type strainer to assess the impact of strainer body size keeping strainer element of same size. They were successful in representing fluid flow distribution and associated pressure drop across strainer.

Literature review reveals that a lot of work has done by researchers on of different kind of filtration methods. Industrial strainers have been less attended by researchers for characterizing their hydraulic performance - predicting pressure drop. Limited numerical work on limited strainer types are reported in the literature. A methodology of investigation to improve the performance of an existing strainer design is found to be not sufficiently established. There is no comprehensive theory for the prediction of hydraulic performances of strainers. Overall, literature in area of computational modeling of strainers seems to be scarcely published.

The present study deals with a 12 inch T-type industrial strainer shown in figure 2. Inlet and outlet diameter are $303.74 \mathrm{~mm}$. It has 40 mesh (36 SWG) of thickness $0.001393 \mathrm{~m}$ with backing of perforate d sheet having $6 \mathrm{~mm}$ hole arranged with $8 \mathrm{~mm}$ triangular pitch. The direction of fluid flow is shown in figure by arrow. The objective of the present work is to develop a numerical methodology to capture the underlying physics accurately and be able to predict pressure drop. It is also intended to carry out a geometrical parametric study for the development of an efficient strainer. The scope of work is limited to the flow rate in the range of $260 \mathrm{~m}^{3} / \mathrm{hr}$ to $470 \mathrm{~m} / \mathrm{hr}$. 
Journal of Thermal Engineering, Technical Note, Vol. 6, No. 6, Special Issue 12, pp. 420-433, December, 2020

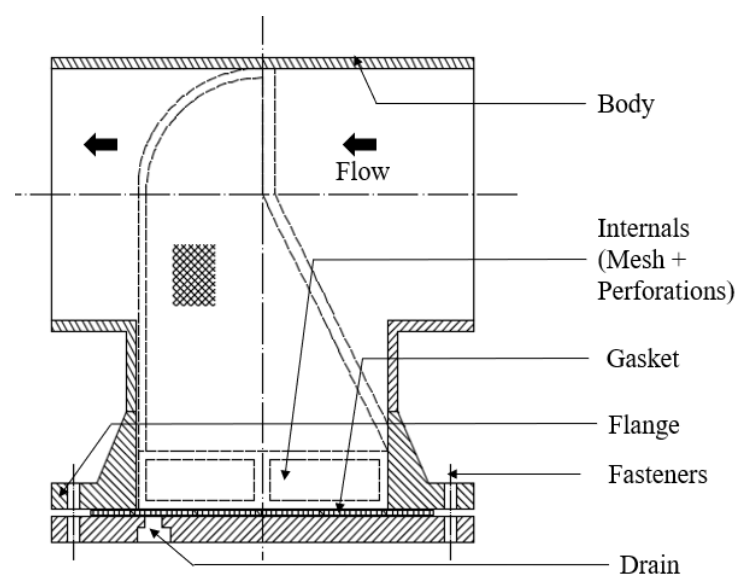

Figure 2. Internalelements of T-type strainer

\section{MATHEMATICAL MODELLING}

The flow through the strainer is assumed to be isothermal steady incompressible Newtonian fluid flow. The body force, viscous forces and pressure gradient are significant contributor to the momentum equation. Viscous and kinetic resistance to flow is dominant. There is no blockage of mesh.

\section{Governing Equations:}

Continuity equation,

$$
\nabla(\rho \vec{V})=0
$$

Momentum equation,

$$
\frac{\partial}{\partial t}(\rho \vec{V})+\nabla(\rho \vec{V} \vec{V})=-\nabla p+\nabla[\mu(\nabla \vec{V})]+\rho \vec{g}
$$

where, the transient term is intentionally shown to update velocity field evolving during iterative solution.

Turbulence Model:

$\mathrm{k}-\omega$ model solves 2 transport equations, one for the turbulent kinetic energy $(\mathrm{k})$, and one for the turbulent frequency $(\omega)$.

k- Equation:

$$
\frac{\partial}{\partial t}(\rho k)+\frac{\partial}{\partial x_{j}}\left(\rho k u_{j}\right)=\frac{\partial}{\partial x_{j}}\left[\left(\mu+\frac{\mu_{t}}{\sigma_{k}}\right) \frac{\partial k}{\partial x_{j}}\right]+P_{k}-\beta^{\prime} \rho k \omega+P_{k b}
$$

$\omega$ - Equation:

$$
\frac{\partial}{\partial t}(\rho \omega)+\frac{\partial}{\partial x_{j}}\left(\rho \omega u_{j}\right)=\frac{\partial}{\partial x_{j}}\left[\left(\mu+\frac{\mu_{t}}{\sigma_{\omega}}\right) \frac{\partial \omega}{\partial x_{j}}\right]+\alpha \frac{\omega}{k} P_{k}-\beta \rho \omega^{2}+P_{\omega b}
$$

All terms represent usual meaning. 
Journal of Thermal Engineering, Technical Note, Vol. 6, No. 6, Special Issue 12, pp. 420-433, December, 2020

\section{Boundary Conditions:}

Inlet: Velocity inlet.

Outlet: Zero gauge pressure.

Walls: No slip.

Porous Jump: The changes taking place in the flow across strainer element can be modelled by an equivalent porous jump condition in the flow domain by the methodology described below.

$$
\text { Pressure Jump, } \Delta P=-\left(\frac{\mu}{\alpha} V+C_{2} \frac{\rho v^{2}}{2}\right) \Delta m
$$

where, $\mathrm{C}_{2}$ is the pressure jump coefficient which is calculated by following mathematical model [9].

$$
C_{2}=\frac{K_{e q}}{t_{p}}
$$

The equivalent pressure drop coefficient $\left(\mathrm{k}_{\mathrm{eq}}\right)$ is given as,

$$
K_{e q}=\left(\frac{K_{w}}{\left({ }^{A_{f}} / A_{t}\right)^{2}}\right)+K_{p}
$$

Now, the pressure drop coefficient of punch plate $\left(K_{p}\right)$ is given by [5],

$$
K_{p}=\frac{0.5\left(1-\beta^{2}\right)+\tau\left(1-\beta^{2}\right)^{1.5}+\left(1-\beta^{2}\right)^{2}+\frac{\lambda_{t}}{d_{h}}}{\beta^{4}}
$$

Porosity of the screen $\left(\beta^{2}\right) i s \beta^{2}=\frac{A_{f}}{A_{t}}$

The tabular coefficient $(\tau)$ depending on $t_{p} / d_{h}$ is found out from hydraulic resistance handbook [10] and friction coefficient $(\lambda)$ found from [11].

Pressure drop coefficient of wire mesh $\left(\mathrm{K}_{\mathrm{w}}\right)$,

$$
K_{w}=\frac{1}{C_{w}^{2}}\left(\frac{1-\alpha_{w}^{2}}{\alpha_{w}^{2}}\right)
$$

Pressure discharge coefficient $\left(\mathrm{C}_{\mathrm{w}}\right)$, calculated from Perry's chemical engineers handbook [9].

\section{NUMERICAL IMPLEMENTATION}

To investigate the problem numerically, the geometry of computational domain is created and meshed through ICEM-CFD as per drawing obtained from M/S Bombay Chemical Equipments, Mumbai. It is shown in figure 3. Meshing is done such that all essential features of strainer can be captured easily. The fluid flow through strainer is considered to be steady. The effect of gravity has been neglected. The cells count in meshing is around 1 million. 


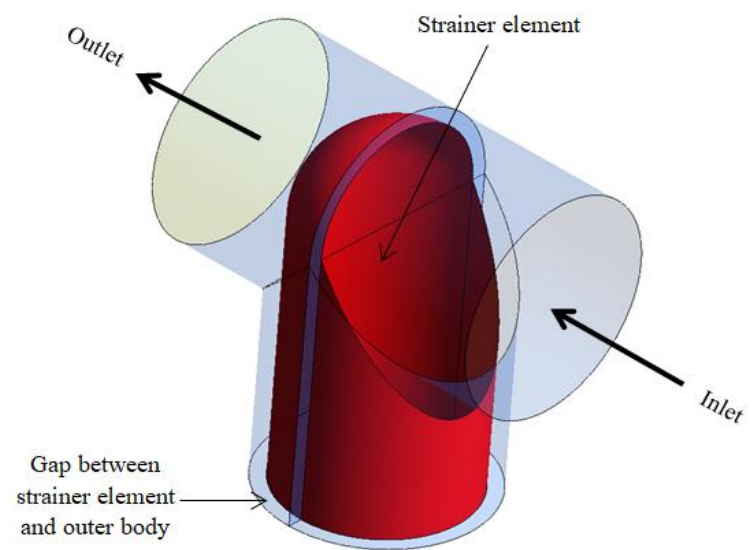

Figure 3. Computationaldomain of a T-type strainer

As the flow is highly turbulent in nature, a number of turbulence models are tested, where $\mathrm{k}-\omega$ SST model is found to be more appropriate for present case. Pressure based SIMPLE algorithm is used to couple pressure and velocity. Second order upwind scheme is used in all cases of upwinding. PRESTO scheme is used as pressure discretization scheme. Under relaxation factors are set as default. Inlet velocity is varied from $1.01 \mathrm{~m} / \mathrm{s}$ to $1.8 \mathrm{~m} / \mathrm{s}$ for different flow rates. Outlet condition is taken as pressure outlet and considered as zero gauge pressure. All solid surfaces are considered to have no slip condition. Strainer elements are given jump condition based on semi-empirical correlation [9].

\section{RESULTS AND DISCUSSION}

\section{Flow Through T-type Strainer:}

The flow resistance is expected as fluid passes through strainer element causing a pressure drop across strainer element. The flow inside bottom pocket of strainer should be supportive to trap foreign particles and debris which are harmful for downstream components. Figure 4 shows pressure and velocity streamlines inside three dimensional computational domain at a flow rate of $264.481 \mathrm{~m}^{3} / \mathrm{hr}$. A drastic drop of pressure across mesh and punch plate can be observed. Majority streamline emerging from inlet directly move towards outlet without significantly influencing trap section of the strainer. This is because of inertia of fluid in the direction of flow. The investigation is performed at several flow rate ranging from $264.481 \mathrm{~m}^{3} / \mathrm{hr}$ to $468.158 \mathrm{~m}^{3} / \mathrm{hr}$. a) The pressure and b) velocity streamlines illustrated respectively, in figure 4 .

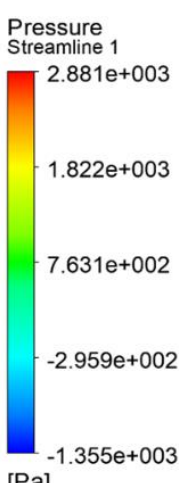

[Pa]

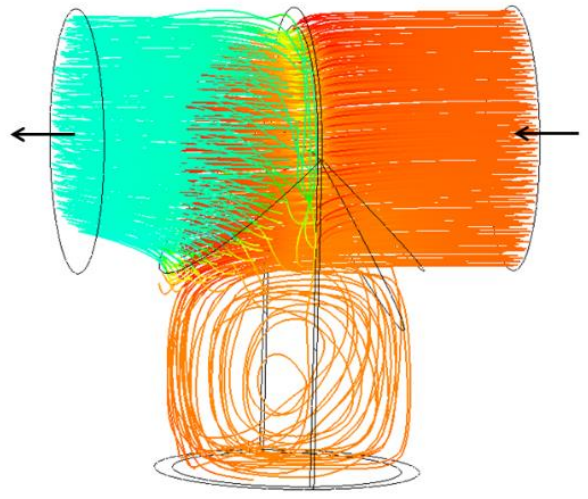

a)

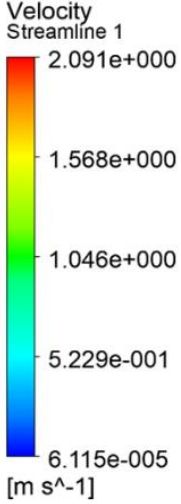

$\left[\mathrm{m} \mathrm{s}^{\wedge}-1\right]$

Figure 4. a) Pressure streamlines and b) velocity streamlines 


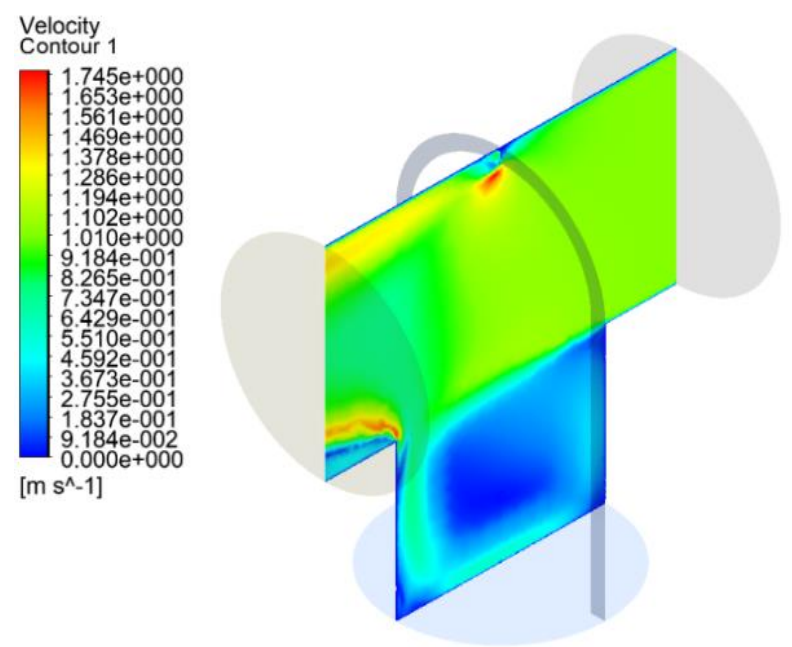

Figure 5. Velocity contours on mid plane along flow direction

The contours of velocity from figure 5 shows that the trap section with stagnation ambience which is favourable for debris to reside before next cleaning operation is performed for the strainer.

In order to validate the model adopted for investigation of strainer, the performance testing of the strainer was done by M/s Bombay Chemical Equipments, Mumbai at testing facilities located at Central Water and Power Research Station, Khadakwasla, Pune. The experiments were conducted on same strainer which were at $100 \%$ clean condition. The pressure drop across strainer is recorded. Normal water without any debris have used as fluid media. The pressure drop was measured on inlet and outlet nozzle across the strainer assembly using gauges. Using semi-empirical formulae available in Perry's handbook [9], calculation for pressure drop was computed. Head loss across strainer,

$$
\Delta h=\Delta h_{s}+\Delta h_{b}
$$

where,

$$
\Delta h_{s}=\frac{1}{C_{w}{ }^{2}}\left[\frac{1-\alpha^{2}}{\alpha^{2}}\right]\left[\frac{V_{s}{ }^{2}}{2 g}\right]
$$

and,

$$
\Delta h_{b}=0.4\left[\frac{V_{b}{ }^{2}}{2 g}\right]
$$

Figure 6 shows the validation of numerical results with experimental data and theoretical calculations. Experimental pressure drop values are in good agreement with numerical values. This figure shows that theoretical method under predicts the pressure drop. 


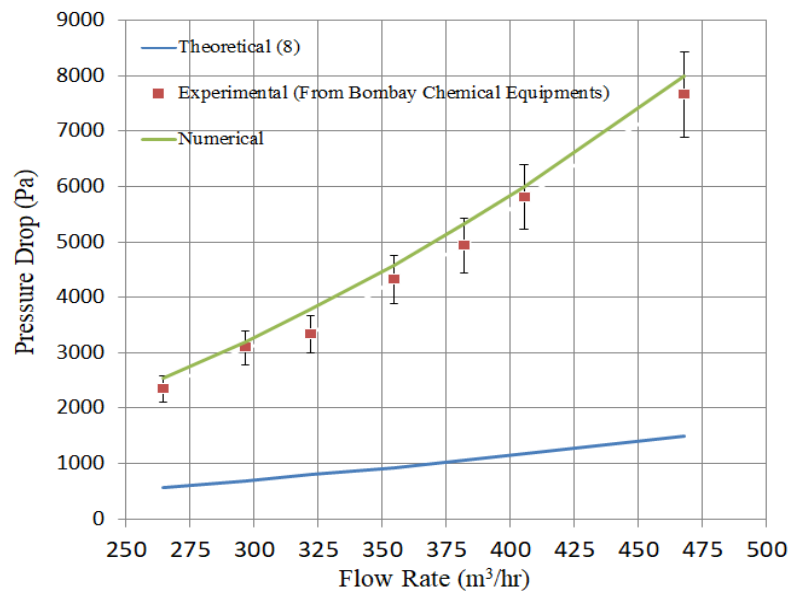

Figure 6. Pressure drop results versus flow rate

\section{Effect of Reynolds Number on Pressure Drop:}

To investigate the effect of Reynolds number on pressure drop, flow rate is varied in the practical range of 15 $\mathrm{m}^{3} / \mathrm{hr}$ to $468.16 \mathrm{~m}^{3} / \mathrm{hr}$. This ensures change in $\mathrm{R}_{\mathrm{e}}$ from 19,600 to $6,11,800$.

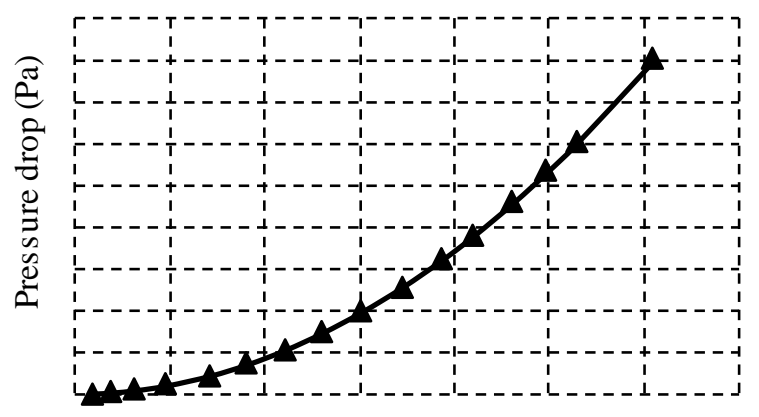

Reynolds Number $\left(\mathrm{x} 10^{3}\right)$

Figure 7. Variation of pressure drop with $\mathrm{R}_{\mathrm{e}}$

Figure 7 shows the variation of pressure drop with increasing $R_{e}$. Pressure drop is nonlinearly increasing with increasing Reynolds number. A correlation between the pressure drop and $\mathrm{R}_{\mathrm{e}}$ can be established through the regression analysis as,

$$
\Delta P=0.0214 R_{e}{ }^{2}-0.016 R_{e}-0.0645
$$

Excessive filtration activity in specific portion of the strainer leads to quick wear and tear which needs frequent replacement of strainer element. On many systems, a robust strainer is desired due to several reasons. In order to avoid this problem and to improve the life of strainer following section present a numerical investigation of strainer where few possible geometrical changes has recommended.

\section{Flow Through Modified Strainer:}

Punch plates are generally used in current strainers as support to mesh element for their longer life and to prevent deformation and erosion. The flow patterns predicted through previous investigation clearly shows that only a specific section of meshing element always has loads of flow which tends to reduce its life and major portion of 
meshing element remain under utilized. To improve the situation, six geometrical modifications of filtering domain have suggested which are represented in Figure 8.

In figure 8 (a) and 8 (b) flow is obstructed by small partition and long partition respectively. Figure 8 (c), 8 (d) and 8 (e) are equipped with punch plate of different configurations. Figure 8 (f) is depicting a new configuration of existing strainer where inlet and outlet are not inline.

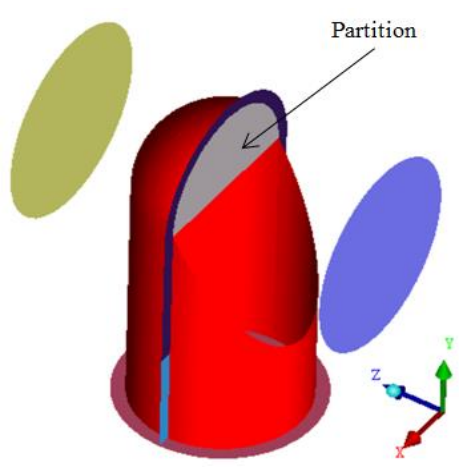

a)

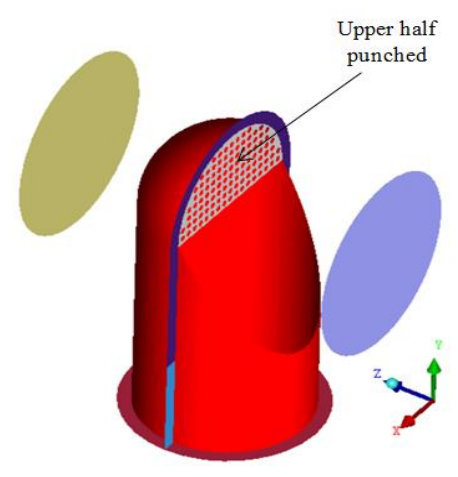

c)

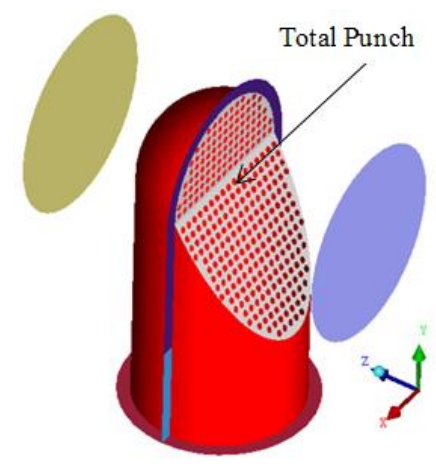

e)

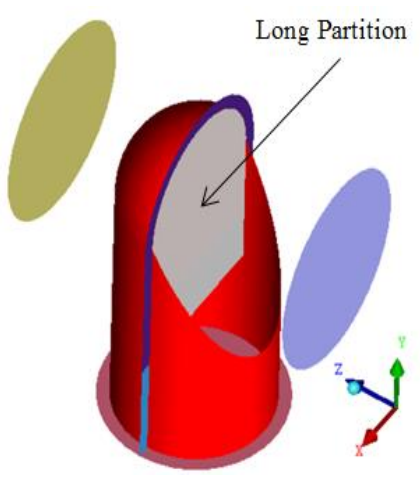

b)

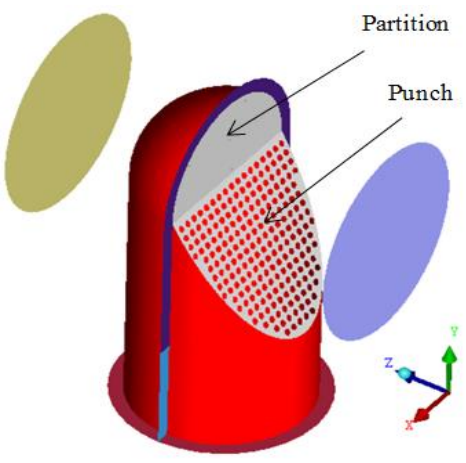

d)

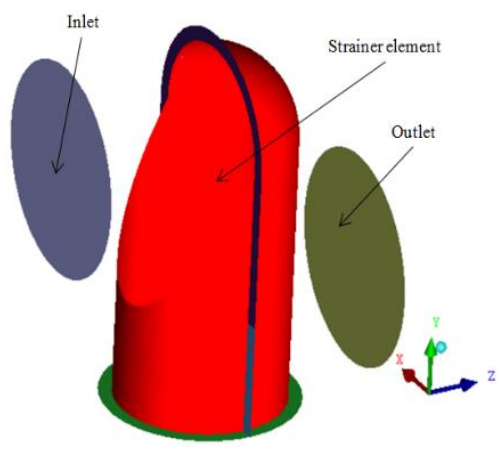

f)

Figure 8. Geometry modifications, a) with small partition,b) with long partition c) with upper half punch and half open d) with lower half punch and half partition e) with total punch f) inlet outlet not inline 
Journal of Thermal Engineering, Technical Note, Vol. 6, No. 6, Special Issue 12, pp. 420-433, December, 2020

At a flow rate of $264.48 \mathrm{~m}^{3} / \mathrm{hr}$, the investigations for all cases have carried out. The streamlines for all 6 cases represented as above are shown in Figure 9.

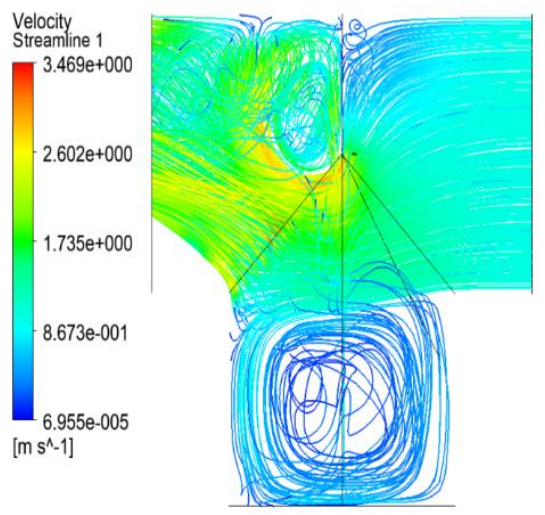

a)

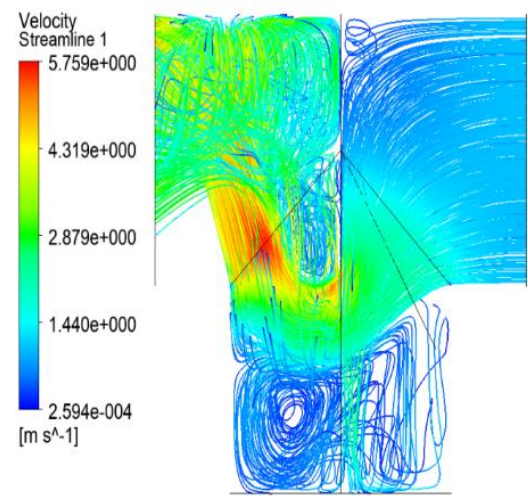

b)

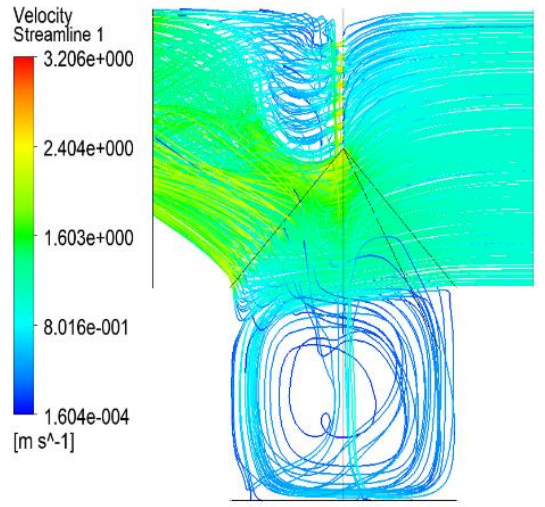

c)

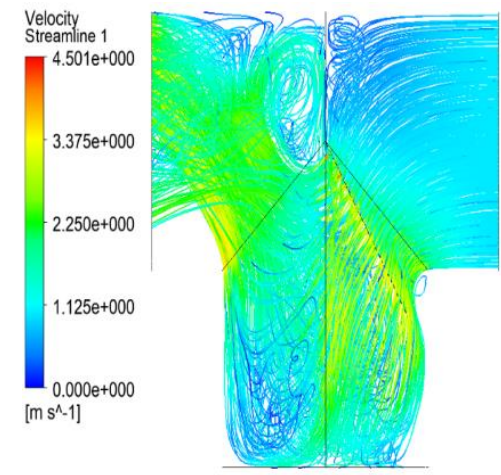

d)

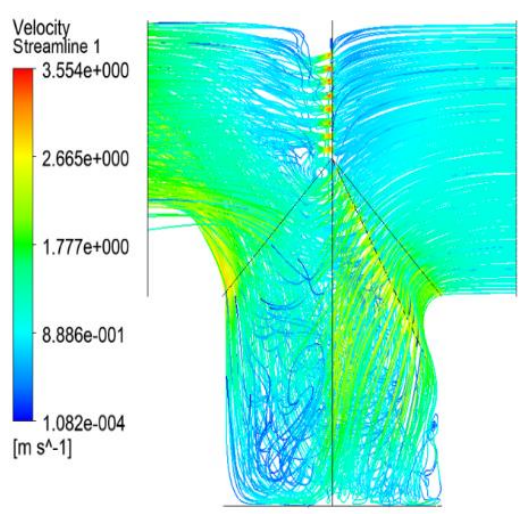

e)

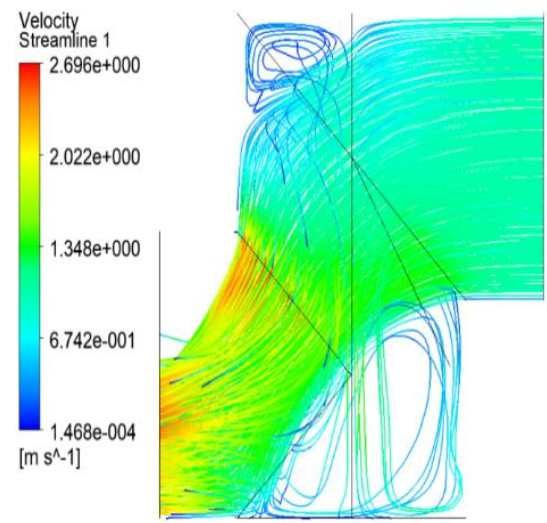

f)

Figure 9. Streamlines of flow under different condition a) with small partition b) with long partition c) with upper half punch and half open d) with lower half punch and half partition e) with total punch $\mathrm{f}$ ) inlet outlet not inline 
A stiff flow resistance is observed under different modifications recommended for longivity and better performance of the strainer. A report of pressure drop across strainer element is listed in the table 1.

Table 1. Pressure drop under various configurations

\begin{tabular}{|c|l|c|}
\hline Sr. no. & Proposed modifications & $\Delta \mathrm{P}(\mathrm{kPa})$ \\
\hline 1. & For small partition & 06.67 \\
\hline 2. & For long partition & 19.40 \\
\hline 3. & $\begin{array}{l}\text { With upper half punched and } \\
\text { lower half open }\end{array}$ & 04.43 \\
\hline 4. & $\begin{array}{l}\text { With lower half punched and } \\
\text { upper half partition }\end{array}$ & 12.08 \\
\hline 5. & With total punch & 07.20 \\
\hline 6. & Inlet outlet not inline & 03.70 \\
\hline
\end{tabular}

Figure 9(f) shows a good flow distribution and least pressure drop among all cases. No punch plate is introduced here. Pressure drop is minimum amongst all. This arrangement appears to be better strainer design configuration for minimum pressure drop and better utilization of mesh element. Only constraint is that incoming and outgoing flow lines would not be inline. With the case of total punch plate partition i.e. configuration $8(\mathrm{e})$ gives better flow distribution and comparatively lower pressure drop among all similar cases. So, this arrangement will be useful in cases where flow distribution is required in strainer and if higher pressure drop is manageable.

\section{Effect of Punch Hole Size of Total Punch Plate:}

The configuration 8 (e) gives lesser pressure drop among all cases with good flow distribution. Punch hole is expected to influence flow distribution and pressure drop significantly. The case has been investigated for the punch holes of size 10,15 and, $20 \mathrm{~mm}$. Figure 10 shows the variation of $\Delta \mathrm{P}$ with punch hole size of punch plate.

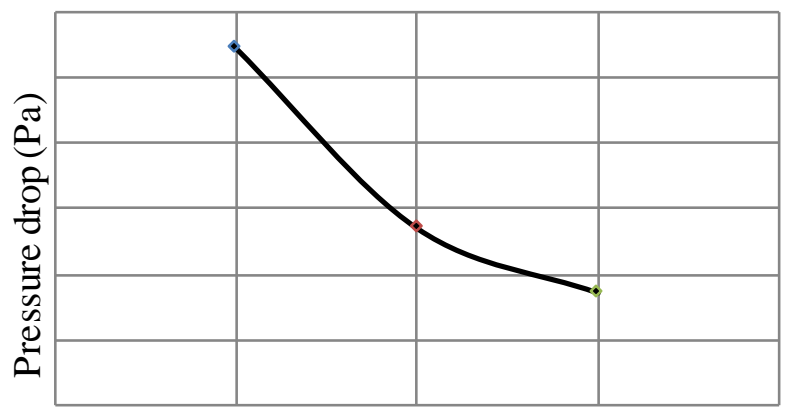

Punch hole diameter (mm)

Figure 10. Effect of punch hole size on pressure drop

The variation of pressure drop is non-linear and decreases with increase of punch hole size. Increase of punch hole from $10 \mathrm{~mm}$ to $15 \mathrm{~mm}$ leads to bigger $\Delta \mathrm{P}$ compared to change in $\Delta \mathrm{P}$ from $15 \mathrm{~mm}$ to $20 \mathrm{~mm}$.

\section{Changing strainer body size while keeping straining element size same}

The investigation report presented in previous sub-sections was for strainer of body size 12 inch. Bigger body size of strainer is a crucial from pressure drop point of view and a significant improvement in performance is expected. This section deals with impact of body size on pressure drop across strainer. The strainer body size considered for investigation are $13 \mathrm{inch}, 14 \mathrm{inch}, 15 \mathrm{inch}$ and $16 \mathrm{inch}$ at a flow rate of $264.48 \mathrm{~m}^{3} / \mathrm{hr}$. Figure 11 shows the variation of outer body from 13 inch to 16 inch by keeping the strainer element same as of original case. 


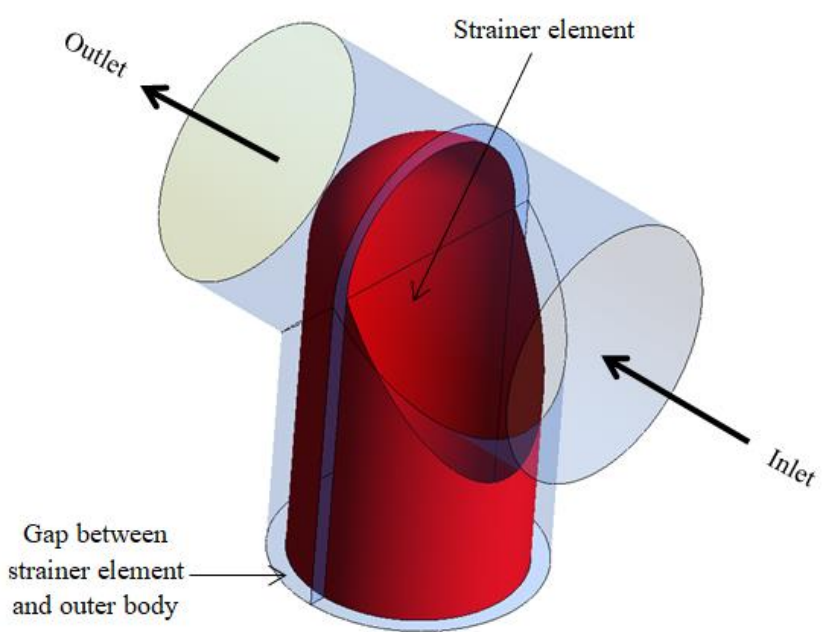

a)

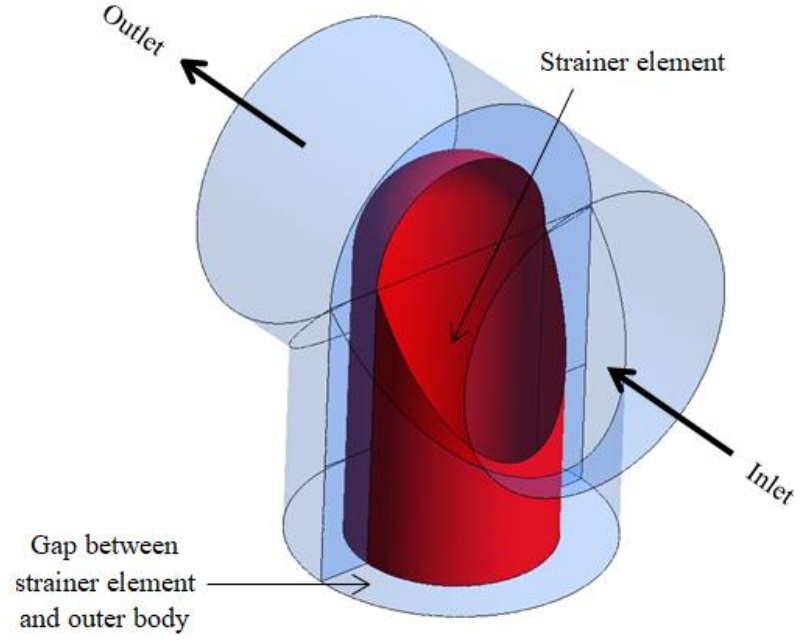

b)

Figure 11. Same strainer element with a) 13 inch and b) 16 inch outer body

An increased gap between strainer mesh and outer body tends to deflect the peripheral annulas fluid towards core and changing the overall momentum of upstream fluid. It makes the flow distribution better and helps in lower the pressure drop. The distribution of pressure and velocity for strainer with 14 inch outerbody size is shown in figure 12.

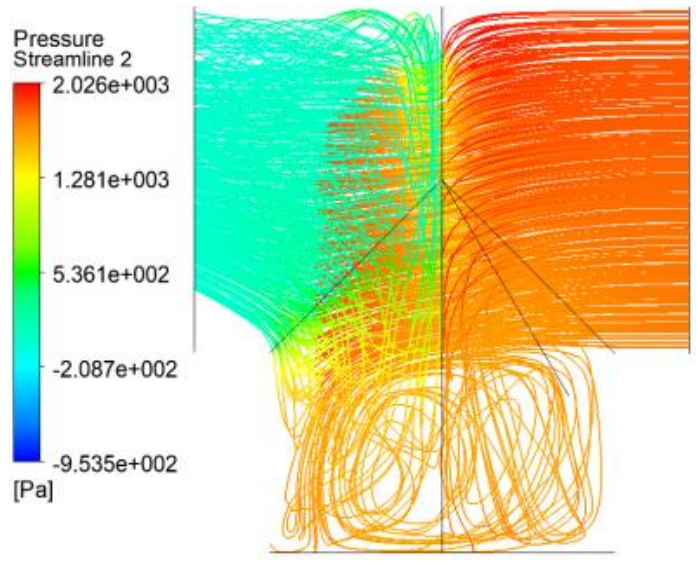

a)

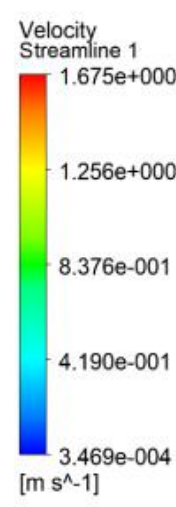

b)

Figure 12. a) Pressure and b) velocity streamlines for strainer size 14 inch

Figure 13 shows a significant non-linear variation of pressure drop with increasing body size of strainer. A variation from 12 inch body size to 16 inch is found to drop about $50 \%$ which is shown in figure 13 . This significant change in pressure drop may attributed to increasing gap between strainer mesh and outer body which acting as damper to the momentum of approaching stream. It causes lesser pressure drop across strainer. 
Journal of Thermal Engineering, Technical Note, Vol. 6, No. 6, Special Issue 12, pp. 420-433, December, 2020

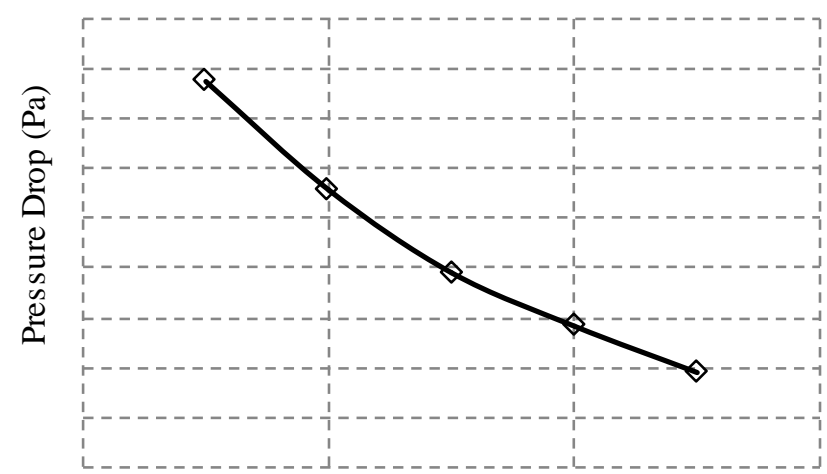

Strainer Body Size (inch)

Figure 13. Effect of strainer body size on pressure drop

\section{Effect of enlarged body size with full punch plate on flow distribution and pressure drop}

It is observed that increasing body size of strainer and introducing a full punch plate (Fig. 8(e)) with increasing punch hole size have positive effect on net pressure drop across strainer. An efficient T-strainer can be proposed by using these outcomes of the investigation. To illustrate the combined effect of both parameters on strainer's pressure drop, a strainer body of size 16 inch with full punch plate of pun ch hole size of $20 \mathrm{~mm}$ is considered for investigation. The solid model's proposed configuration is shown in figure 14 .

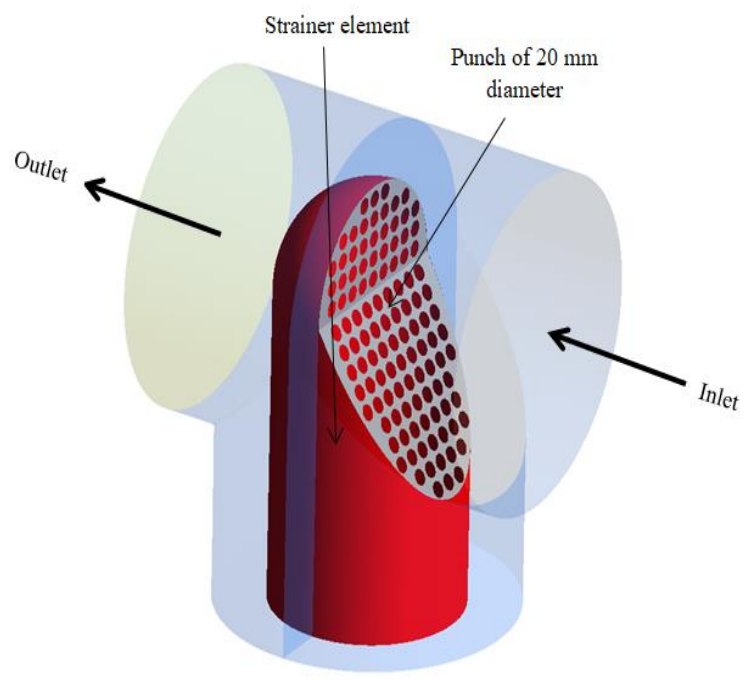

Figure 14. Optimum variation for strainer

The pressure and velocity distribution on a mid plane along flow direction is represented in figure 15. A drop of pressure across punch plate and development of a stagnant zone (little increase in pressure) due to flow obstruction created by meshing element can be observed. Further drop of pressure across meshing element can be observed. The pressure drop found to be $2.37 \mathrm{kPa}$ at a flow rate of $264.48 \mathrm{~m}^{3} / \mathrm{hr}$, Velocity is uniformly distributed and well balanced from longevity and erosion point of view. 


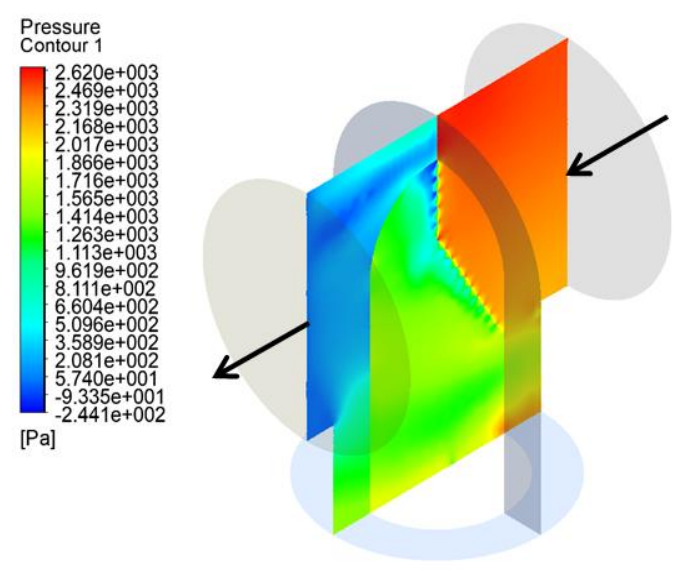

a)

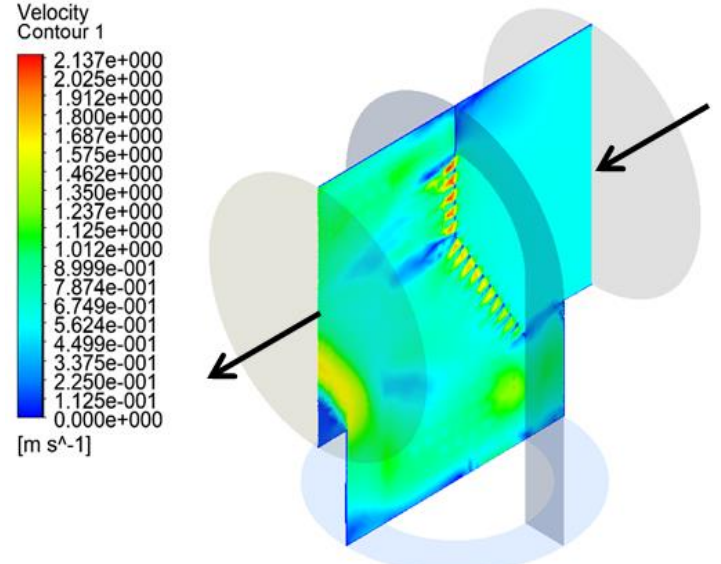

b)

Figure 15. a) Pressure and b) velocity distribution on mid plane along flow direction

\section{CONCLUSION}

Present work deals with a numerical investigation of pressure drop across T-type Strainer. A numerical methodology has proposed to estimate pressure jump coefficient which is crucial for numerical investigation. The work has been validated with a test rig data of strainer, conducted by Bombay Chemical Equipments, Mumbai. The effect of $R_{e}$ on pressure drop is also investigated which increases with $R_{e}$. Six geometrical modifications for punch plate have proposed to be placed ahead of straining element. Total punch plate configuration is found to be most efficient amongst all. Variation of punch hole size is also investigated. It is found that bigger diameter is more appropriate without losing strength of the punch plate. Further investigation is carried out for bigger bod y size of strainer, a drastic drop in pressure drop is observed. An illustration of combining all good features for lesser pressure is found to be a good predictive methodology. Present investigation is useful for the strainer designer and fabricator to select a proper strainer for a specific application.

\section{NOMENCLATURE}

$\mathrm{A}_{\mathrm{f}} \quad$ Open area of Strainer

$A_{t} \quad$ Curved surface area of strainer element

$\alpha \quad$ Permeability of the medium

$\alpha_{\mathrm{w}} \quad$ Opening area ratio of mesh screen

$\beta \quad$ Equivalent diameter ratio

$\beta^{2} \quad$ The porosity of the screen

$\mathrm{C}_{2} \quad$ Pressure jump coefficient

$\mathrm{C}_{\mathrm{w}} \quad$ Pressure discharge coefficient for wire mesh

$\mathrm{d}_{\mathrm{h}} \quad$ Hole diameter of punch plate

$\Delta \mathrm{h} \quad$ Total head loss

$\Delta \mathrm{h}_{\mathrm{b}} \quad$ Head loss across body

$\Delta \mathrm{h}_{\mathrm{s}} \quad$ Head loss across screen

$\Delta \mathrm{m} \quad$ Thickness of the medium

$\Delta \mathrm{P} \quad$ Pressure drop

g Acceleration due to gravity

$\mathrm{K}_{\mathrm{eq}} \quad$ Equivalent pressure drop coefficient

$\mathrm{K}_{\mathrm{p}} \quad$ Pressure drop coefficient of punch plate 
Journal of Thermal Engineering, Technical Note, Vol. 6, No. 6, Special Issue 12, pp. 420-433, December, 2020

\author{
$\mathrm{K}_{\mathrm{W}} \quad$ Pressure drop coefficient of wire mesh \\ $\mathrm{P}_{\mathrm{k}} \quad$ Production rate of turbulence \\ Q Flow rate \\ $\mathrm{Re}_{\mathrm{e}} \quad$ Reynolds number \\ $\rho \quad$ Density of fluid \\ $t_{p} \quad$ Thickness of internals of strainer element which is used as porous jump thickness. \\ $\tau \quad$ Tabular coefficient \\ $\mu \quad$ Fluid viscosity \\ $\mathrm{V}_{\mathrm{s}} \quad$ Velocity ahead of screen \\ $\mathrm{V}_{\mathrm{b}} \quad$ Velocity through body \\ $\vec{v} \quad$ Velocity vector \\ $\lambda \quad$ Friction coefficient \\ CFD Computational fluid dynamics \\ SIMPLE Semi-Implicit Method for Pressure-Linked Equations \\ SST Shear stress transport \\ SWG Standard wire gauge
}

\title{
REFERENCES
}

[1] Carlomagno M, Rossin S, Delvecchio M, Anichini A. Experimental and numerical validation of conical strainer fluid/structural performance model. Proc. ASME Turbo Expo, vol. 6, American Society of Mechanical Engineers Digital Collection; 2012,p. 155-71.https://doi.org/10.1115/GT2012-69751.

[2] JW K, JA K, EY K, CM J, DH K, HN C. CFD Analysis of Liquid Stream Going Through the Wire-Screen Mesh. 5th Int Conf Heat Transf Fluid Mech Thermodyn 2007.

[3] Erdal A, Andersson HI. Numerical aspects of flow computation through orifices. Flow Meas Instrum 1997. https://doi.org/10.1016/S0955-5986(97)00017-4.

[4] Iliev O, Laptev V. On numerical simulation of flow through oil filters. Comput Vis Sci 2004. https://doi.org/10.1007/s00791-003-0118-8.

[5] Malavasi S, Messa G, Fratino U, Pagano A. On the pressure losses through perforated plates. Flow Meas Instrum 2012.https://doi.org/10.1016/j.flowmeasinst.2012.07.006.

[6] Barros Filho JA, Navarro MA, Dos Santos A, Jordão E. Experimental and CFD Simulations of Pressure Loss through Perforated Plates. J Energy 2011.

[7] Tekam SM, Demoulin M, Tekam SM, Daru V. Comparison of numerical and experimental methods for predicting the efficiency of an automotive oil strainer. Am. Soc. Mech. Eng. Fluids Eng. Div. FED, 2004. https://doi.org/10.1115/IMECE2004-59971.

[8] Gaurav PM, Maurya RS, Mujumdar K. Numerical investigation and performance evaluation of T-type industrial strainer. Int. Conf. Therm. Fluid Eng., 2017.

[9] Perry's chemical engineers' handbook. Choice Rev Online 2008. https://doi.org/10.5860/choice.45 -4393.

[10] Weber LJ, Cherian MP, Allen ME, Muste M. Headloss characteristics for perforated plates and flat bar screens. 2000.

[11] Miller DS. Internal flow systems. CRANFIELD, UK, BHRA (INFORMATION Serv 1990. https://doi.org/10.1016/0017-9310(80)90104-0. 